\title{
Design, Synthesis, Crystal Structure and Photoluminescence Properties of Four New Europium (III) Complexes with Fluorinated $\beta$-Diketone Ligand
}

\author{
Tetsuji Moriguchi ${ }^{*}$, Hiromasa Kawata ${ }^{1}$, Venkataprasad Jalli ${ }^{2}$ \\ ${ }^{1}$ Department of Applied Chemistry, Faculty of Engineering, Kyushu Institute of Technology, Kitakyushu, Japan \\ ${ }^{2}$ Sankar Foundation, Research and Development Division, Visakhapatnam, India \\ Email: *moriguch@che.kyutech.ac.jp
}

How to cite this paper: Moriguchi, T., Kawata, H. and Jalli, V. (2021) Design, Synthesis, Crystal Structure and Photoluminescence Properties of Four New Europium (III) Complexes with Fluorinated $\beta$-Diketone Ligand. Crystal Structure Theory and Applications, 10, 1-13.

https://doi.org/10.4236/csta.2021.101001

Received: January 12, 2021

Accepted: February 1, 2021

Published: February 4, 2021

Copyright $\odot 2021$ by author(s) and Scientific Research Publishing Inc. This work is licensed under the Creative Commons Attribution International License (CC BY 4.0).

http://creativecommons.org/licenses/by/4.0/

(c) (i) Open Access

\begin{abstract}
The strong photoluminescence properties of europium complexes with organic ligands attracted the attention of many researchers and found a wide range of uses in medical, industrial and biological fields. In this article, four new Tetrakis europium complexes $\mathbf{3 a}, \mathbf{3 b}, \mathbf{3} \mathbf{c}$ and $\mathbf{3 d}$ have been prepared using 1-phenyl-4,4,4-trifluoro-1,3-butenedionato ligand and pyridinium, bipyridinium, piperazinium and piperidinium counter cations. These complexes have been characterized by negative FAB-mass. The crystal structures of $\mathbf{3 a}$, $3 \mathrm{~b}, 3 \mathrm{c}$ and $\mathbf{3 d}$ were determined by single crystal X-ray diffraction analysis. The complex 3 a crystallized in monoclinic form, space group $P 2_{1} / n$ with four molecules in the unit cell. The complex $\mathbf{3 b}$ crystallized in monoclinic form, space group $P 2 / n$ with two complex molecules in the unit cell. The complex $3 \mathrm{c}$ crystallized in monoclinic form, space group $\mathrm{C} / \mathrm{c}$ with sixteen molecules in the unit cell. The complex $\mathbf{3 d}$ crystallized in monoclinic form, space group $P 2_{1} / n$ with four complex molecules in the unit cell. The complex $3 \mathbf{a}$ has 1,2-alternative structure, $3 \mathbf{b}$ has 1,3 -alternative structure, $3 \mathbf{c}$ has cone like structure and $\mathbf{3 d}$ has partial cone like structure. The photoluminescence properties of these complexes have been evaluated. Strong red emissions were observed in all four complexes due to ${ }^{5} \mathrm{D}_{0} \rightarrow{ }^{7} \mathrm{~F}_{2}$ transition of Europium (III) ions under UV excitation. Four $\beta$-diketone ligands acted as strong antenna ligands and transferred the absorbed energy to europium (III) ion effectively; consequently strong red luminescence was observed.
\end{abstract}

\section{Keywords}

Tetrakis Europium Complexes, Luminescence, Fluorinate $\beta$-Diketone Ligand, 
Pyridine, Bipyridine, Piperazine, Bipiperidine

\section{Introduction}

The photoluminescence properties of Lanthanide complexes with organic ligands have been greatly enhanced, and led to the development of strong luminescent Lanthanide complexes with important applications in medical, industrial and biological fields [1]-[7]. Europium (III) complex with organic ligands is an example of strong luminescent Lanthanide complex and Europium (III) complexes that have great importance in materials engineering chemistry due to significant improvement in photophysical parameters such as high luminescence emission efficiency, long fluorescence life time, large stokes shift, sharp emission bands [8] [9] [10] [11]. In the past decade various high luminescent europium complexes have been engineered and evaluated for their photoelectronic properties such as OLEDs, electroluminescent displays, bioimaging, sensing and targeting specific DNA structures, melamine detection in milk protein. Europium (III) complexes have also found applications as sensor materials to detect pesticides, temperature, $\mathrm{HCl}, \mathrm{NO}_{2}$ gas, $\mathrm{HOCl}, \mathrm{pH}$, phosphate, mitochondria and, 8-oxo-dGTP [12]-[20]. Albumin proteins in human serum have also been detected by Europium complexes, which act as sensor materials [21].

Search for novel europium complexes that uses less energy and exhibits desired application such as sensors, OLEDS, etc. is of great importance in photoelectronic materials. Therefore, new europium complexes should have enhanced degree of change in luminescence to be a good sensor material. On the other hand, understanding the relationship between molecular structures and photoelectronic properties of europium (III) complexes gives valuable information in designing future photoelectronic materials with improved properties. It is stated that luminescence of Europium (III) ion originates from forbidden $\mathrm{f}-\mathrm{f}$ transitions that totally hinder the Europium (III) ion interaction with light. The ligand that forms complexes with Europium (III) ion acts as antenna. This absorbs energy and transfers to Europium (III) ion through intersystem crossing to triplet excited states. In this context, europium complexes with substituted aromatic $\beta$-diketones as organic ligands were explored due to efficiency in generating triplet excited states in close contact with europium (III) ion. Thus, various Europium (III) complexes with $\beta$-diketones were synthesized and evaluated for their photoluminescent properties [22] [23] [24] [25] [26].

In our previous studies, we synthesized and investigated the molecular structures and photoelectronic properties of octa-coordinate europate (III) complexes using substituted $\beta$-diketone ligands [27] [28]. In this study, we want to investigate the molecular structures and photoluminescence properties of four new octa-coordinate Europium (III) complexes $3 \mathrm{a}, 3 \mathrm{~b}, \mathbf{3 c}$ and $\mathbf{3 d}$, possessing pyridinium, bipyridinium, piperazinium and bipiperidinium as counter cations. 


\section{Experimental}

\subsection{Materials and Methods}

Reagent grade europium (III) chloride, pyridine, bipyridine, piperazine and bipiperidine were purchased from the TCI chemicals industry, Tokyo and used as such to prepare europium complexes. The ligand 1-phenyl-4,4,4-trifluoromethyl1,3-butanedione was synthesized in the laboratory. The positive fast atom bombardment (FAB) mass spectrum (MS) of the complexes was obtained on a Nippon Densi JEOL JMS-SX102A spectrometer (JEOL, Tokyo, Japan) using NBA (nitrobenzyl alcohol) as the matrix and DCM (dichloromethane) as the solvent. The instrument was operated in negative ion mode over an $\mathrm{m} / \mathrm{z}$ range of 100 2000. Elemental analysis data were recorded on a Yanako MT-4 analyzer (Yanako Group, Kyoto, Japan). A JASCO V-550 spectrophotometer (JASCO Corporation, Tokyo, Japan) was used for obtaining UV-Vis spectra in dichloromethane with 250 - $900 \mathrm{~nm}$ range. HITACHI F-8700 spectrophotometer (Hitachi High-Technologies Corporation, Tokyo, Japan) was used for fluorescence spectra measurements in dichloromethane with 250 - $900 \mathrm{~nm}$ range. CCDC No. 1962454, 2047729, 1563207 and 1563206 contain the supplementary crystallographic data for the complexes $3 a, 3 b, 3 c$ and $3 d$, respectively.

\subsection{General Procedure for the Synthesis of Complexes 3a, 3b, 3c and $3 d$}

In a RB flask, a solution of europium (III) chloride $(0.650 \mathrm{~g}, 0.41 \mathrm{mmol})$ and 1-phenyl-4,4,4-trifluoromethyl-1,3-butanedione 1 ( $0.370 \mathrm{~g}, 1.65 \mathrm{mmol})$ in absolute ethanol $(30 \mathrm{~mL})$ was prepared at room temperature. Under protection from air, slightly excess of pyridine, bipyridine, piperazine, bipiperidine were added to the solution to get complexes $\mathbf{3 a}, \mathbf{3 b}, \mathbf{3 c}$ and $\mathbf{3 d}$ respectively. Ethanol was removed by rotary evaporator under reduced pressure. Under protection from air, the residue was repeatedly washed with small portions $(5 \mathrm{~mL})$ of warm, dry ethanol. The residual powders were dissolved in ethanol for crystallization. Without protection from air, the crystallized product was filtered off, washed with two portions of cold ethanol, and dried under reduced pressure, affording the complexes $\mathbf{3 a}, \mathbf{3 b}, \mathbf{3 c}$ and $\mathbf{3 d}$ as a powder. All four complexes were obtained in moderate to good yields ( $68 \%$ for $3 a, 65 \%$ for $3 b, 75 \%$ for $3 c$ and $60 \%$ for $3 d$, respectively).

\subsection{Single-Crystal X-Ray Analysis and Structure Determination}

Crystals of four compounds $3 \mathrm{a}, 3 \mathrm{~b}, \mathbf{3 c}$ and $\mathbf{3 d}$ were obtained at room temperature by crystallization in DCM-ethanol mixed solvent.

The crystal data were recorded on a Bruker APEX II KY CCD diffractometer equipped with graphite monochromatized Mo-Ka radiation of wavelength $0.71073 \AA$ from a sealed micro focus tube, and a nominal crystal to area detector distance of $58 \mathrm{~mm}$. X-ray generator settings were $50 \mathrm{kV}$ and $30 \mathrm{~mA}$. The data were collected at $-153^{\circ} \mathrm{C}(120 \mathrm{~K})$ for $3 b-3 \mathrm{c}$ and at $-123^{\circ} \mathrm{C}(150 \mathrm{~K})$ for $3 a$. 
The crystallographic data of these complexes were summarized in Table 1. APEX2 software was used for preliminary determination of the unit cell [29]. Determination of integrated intensities and unit cell refinement were performed using SAINT program [30]. The structures were solved with SHELXS-2014/7 [31] and subsequent structure refinements were performed with SHELXL-2014/7.

\section{Results and Discussion}

Complexes $\mathbf{3 a}, \mathbf{3 b}, \mathbf{3 c}$ and $\mathbf{3 d}$ were synthesized from the corresponding ligand 1,3-diphenyl-1,3-propanedione by complexation reaction with europium (III) chloride in the presence of pyridine, bipyridine, piperazine and bipiperidine as counter cations (Scheme 1). This reaction is a standard preparation procedure

Table 1. Crystallographic data for the complexes (3a, 3b, 3c and $3 d)$.

\begin{tabular}{|c|c|c|c|c|}
\hline Parameters measured & $3 a$ & $3 b$ & $3 c$ & $3 d$ \\
\hline Empirical formula & $\mathrm{C}_{45} \mathrm{H}_{30} \mathrm{Eu}_{1} \mathrm{~F}_{12} \mathrm{NO}_{8}$ & $\mathrm{C}_{50} \mathrm{H}_{33} \mathrm{Eu} \mathrm{F}_{12} \mathrm{~N}_{2} \mathrm{O}_{8}$ & $\mathrm{C}_{44} \mathrm{H}_{35} \mathrm{Eu}_{1} \mathrm{~F}_{12} \mathrm{~N}_{2} \mathrm{O}_{8}$ & $\mathrm{C}_{45} \mathrm{H}_{35} \mathrm{Eu}_{1} \mathrm{~F}_{12} \mathrm{NO}_{8}$ \\
\hline Formula weight & 1092.67 & 1169.8 & 1099.71 & 1097.71 \\
\hline Crystal shape, color & Prism, colorless & Prism, colorless & Prism, colorless & Prism, colorless \\
\hline Temperature & $150 \mathrm{~K}$ & $120 \mathrm{~K}$ & $120 \mathrm{~K}$ & $120 \mathrm{~K}$ \\
\hline Radiation type & Mo K $\alpha$ & Mo K $\alpha$ & Mo K $\alpha$ & Mo K $\alpha$ \\
\hline Wavelength $(\AA)$ & 0.71073 & 0.71073 & 0.71073 & 0.71073 \\
\hline Crystal system & Monoclinic & Monoclinic & Monoclinic & Monoclinic \\
\hline Space group & $P 2_{1} / n$ & $P 2 / n$ & $C 2 / \mathrm{c}$ & $P 2_{1} / n$ \\
\hline \multirow{4}{*}{ Unit cell dimensions } & $\mathrm{a}=11.144(11) \AA$ & $\mathrm{a}=12.711(4) \AA$ & $a=36.894(5) \AA$ & $\mathrm{a}=11.547(19) \AA$ \\
\hline & $\mathrm{b}=22.034(2) \AA$ & $\mathrm{b}=12.672(4) \AA$ & $\mathrm{b}=22.068(3) \AA$ & $\mathrm{b}=21.886(4) \AA$ \\
\hline & $c=18.770(2) \AA$ & $c=14.755(5) \AA$ & $c=21.916(3) \AA$ & $c=18.005(3) \AA$ \\
\hline & $\beta=107.112(1)^{\circ}$ & $\beta=99.126(3)^{\circ}$ & $\beta=92.682(1)^{\circ}$ & $\beta=99.550(2)^{\circ}$ \\
\hline Cell volume & $4405.1(8) \AA^{3}$ & $2360.9(13) \AA^{3}$ & $17,825(1) \AA^{3}$ & $4487.1(13) \AA^{3}$ \\
\hline $\mathrm{Z}$ & 4 & 2 & 16 & 4 \\
\hline Calculated density & $1.648 \mathrm{~g} / \mathrm{cm}^{3}$ & $1.643 \mathrm{~g} / \mathrm{cm}^{3}$ & $1.639 \mathrm{~g} / \mathrm{cm}^{3}$ & $1.625 \mathrm{~g} / \mathrm{cm}^{3}$ \\
\hline Absorption coefficient & $1.53 \mathrm{~mm}^{-1}$ & $1.433 \mathrm{~mm}^{-1}$ & $1.512 \mathrm{~mm}^{-1}$ & $1.501 \mathrm{~mm}^{-1}$ \\
\hline $\mathrm{F}(000)$ & 2168 & 1164 & 8768 & 2188 \\
\hline Crystal size (mm) & $0.35 \times 0.35 \times 0.10$ & $0.20 \times 0.15 \times 0.10$ & $0.43 \times 0.25 \times 0.10$ & $0.15 \times 0.15 \times 0.10$ \\
\hline $\mathrm{T}$ Theta range for data collection & $1.5^{\circ}$ to $29^{\circ}$ & $1.54^{\circ}$ to $20.48^{\circ}$ & $1.075^{\circ}$ to $25.027^{\circ}$ & $1.48^{\circ}$ to $24.97^{\circ}$ \\
\hline \multirow{3}{*}{ Limiting Indices } & $-14 \leq h \leq 14$ & $-15 \leq h \leq 15$ & $-43 \leq h \leq 43$ & $-13 \leq h \leq 13$ \\
\hline & $-29 \leq k \leq 29$ & $-15 \leq k \leq 15$ & $-26 \leq k \leq 26$ & $-25 \leq k \leq 25$ \\
\hline & $-24 \leq 1 \leq 24$ & $-17 \leq 1 \leq 17$ & $-26 \leq 1 \leq 26$ & $-21 \leq 1 \leq 21$ \\
\hline Reflections & $52,471 / 11,725$ & $4258 / 20,234$ & $15,738 / 84,697$ & $7862 / 41,761$ \\
\hline collected/unique & {$[\mathrm{R}(\mathrm{int})=0.037]$} & {$[\mathrm{R}(\mathrm{int})=0.084]$} & {$[\mathrm{R}($ int $)=0.0321]$} & {$[\mathrm{R}(\mathrm{int})=0.049]$} \\
\hline Completeness to theta ${ }^{\circ}$ & $100 \%$ & $99.0 \%$ & $99.9 \%$ & $99.8 \%$ \\
\hline
\end{tabular}




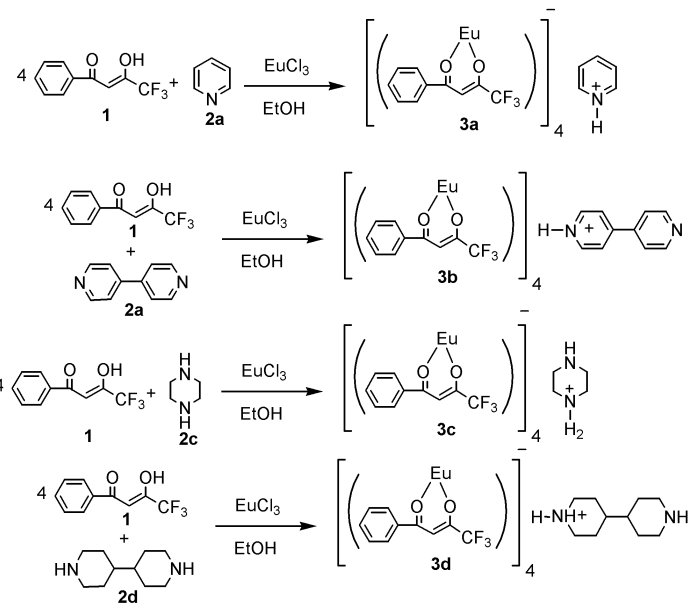

Scheme 1. Reaction scheme for the preparation of $3 a, 3 b, 3 c$ and $3 d$.

for lanthanide (III) complex [32]. Structures of complexes were determined by mass spectrometry and X-ray single crystal structure analyses.

We have measured the UV-Vis and Fluorescence spectra of $3 a, 3 b, 3 c$ and $3 d$. The UV-Vis and Fluorescence spectra of $\mathbf{3 a}, \mathbf{3 b}, \mathbf{3 c}$ and $\mathbf{3 d}$ were measured in solution phase (dichloromethane, $1 \times 10^{-5} \mathrm{~mol} / \mathrm{L}$ ).

The fluorescence spectrum was measured in solution and solid state as well. The solution state fluorescence measurements were carried out in dichloromethane solution $\left(1 \times 10^{-3} \mathrm{~mol} / \mathrm{L}\right)$. The corresponding absorption and emission spectrum of $3 a, 3 b, 3 c$ and $3 d$ were shown below (Figures $1-8$, respectively). Complexes $\mathbf{3 a}, \mathbf{3 b}, \mathbf{3 c}$ and $\mathbf{3 d}$ exhibited absorption maxima at $327,330,326$ and $313 \mathrm{~nm}$, respectively. These strong absorption bands were assigned to the $\pi-\pi^{\star}$ enol absorptions of the $\beta$-diketone ligand.

The fluorescence spectrum of $\mathbf{3} \mathbf{a}$ was measured by exiting the complex at 379 $\mathrm{nm}$ in solution and $307 \mathrm{~nm}$ in solid state. Strong emission band was observed from 600 to $630 \mathrm{~nm}$. The complex $3 \mathrm{~b}$ was exited at $379 \mathrm{~nm}$ in solution and 368 $\mathrm{nm}$ in solid state. Strong emission band was observed from 590 to $620 \mathrm{~nm}$.

The fluorescence spectrum of $3 c$ was measured by exiting the complex at 378 $\mathrm{nm}$ in solution and $307 \mathrm{~nm}$ in solid state. Strong emission band was observed from 600 to $650 \mathrm{~nm}$. The complex 3d was exited at $377 \mathrm{~nm}$ in solution and 306 $\mathrm{nm}$ in solid state. Strong emission band was observed from 610 to $653 \mathrm{~nm}$.

Suitable single crystals for X-ray structure analysis were easily obtained for all complexes. Since, europium (III) complexes are air stable, preparation of crystals is has been easy. All four complexes were dissolved in suitable solvents and left to slow evaporation at room temperature that resulted in crystals of complex $3 \mathrm{a}$, $3 \mathrm{~b}, 3 \mathrm{c}$ and $3 \mathrm{~d}$.

The complex $3 \mathrm{a}$ has 1,2-alternative structure, $3 \mathbf{b}$ has 1,3-alternative structure, $3 \mathrm{c}$ has cone like structure and $\mathbf{3 d}$ has partial cone like structure. In the crystal, complex 3a crystallized in monoclinic form with $P 2_{1} / n$ space group and it has four molecules in unit cell with pyridinium cation (Figure 9). The complex $3 \mathrm{~b}$ also crystallize monoclinic form with $P 2 / n$ space group and it has two molecules 


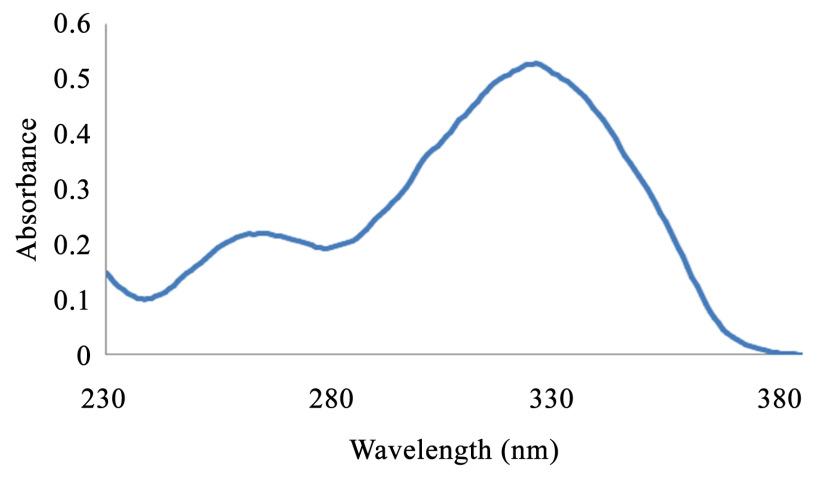

Figure 1. UV-Vis spectra of complex $3 a$.

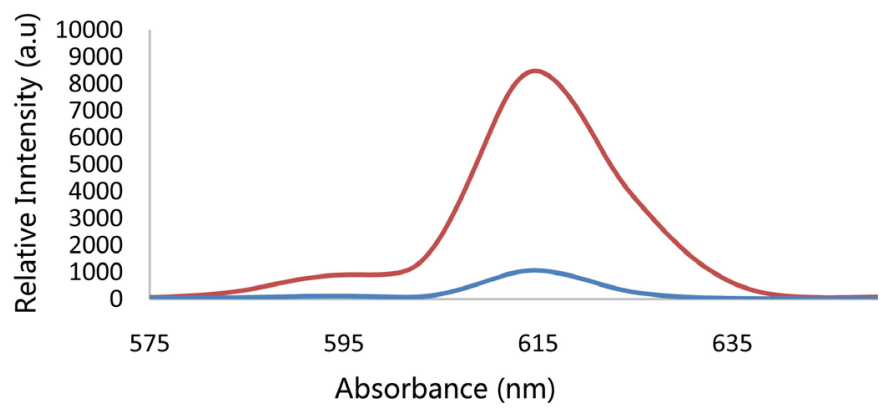

Figure 2. Emission spectra of complex 3a. Blue and red color represents, spectrum in solution and solid phase, respectively.

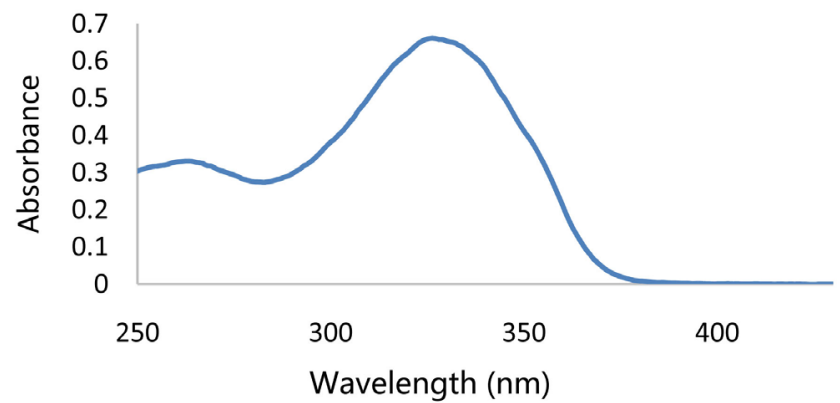

Figure 3. UV-Vis spectra of complex $3 \mathbf{b}$.

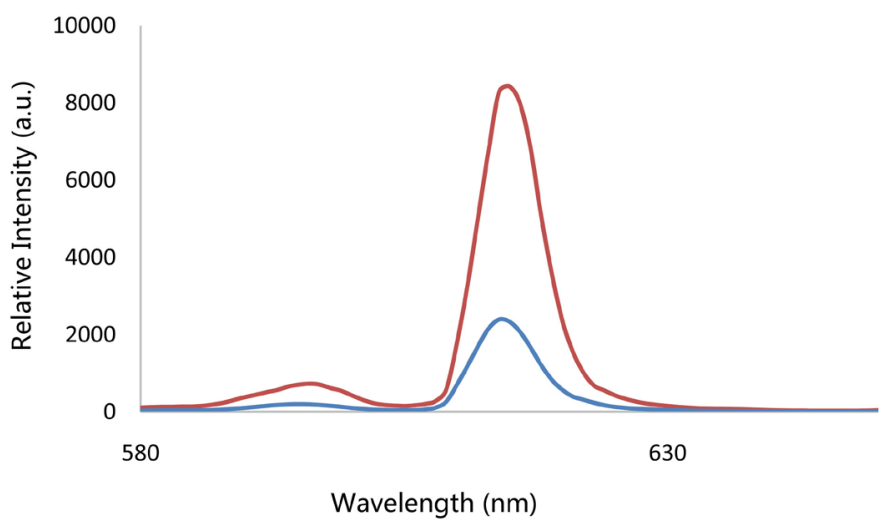

Figure 4. Emission spectra of complex $3 \mathrm{~b}$. Blue and red color represents, spectrum in solution and solid state, respectively. 


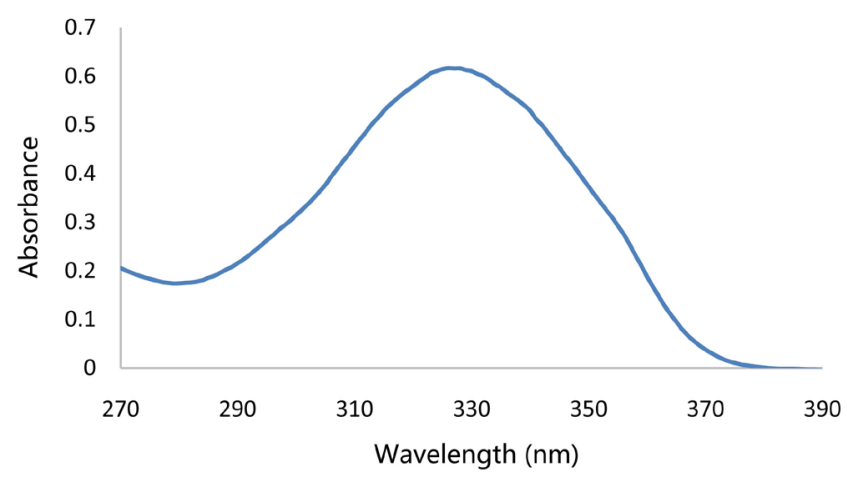

Figure 5. UV-Vis spectra of complex 3c.

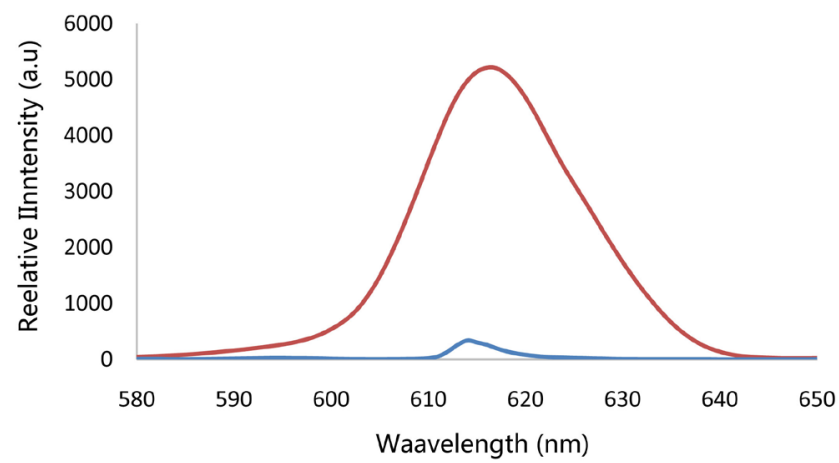

Figure 6. Emission spectra of complex 3c. Blue and red color represents, spectrum in solution and solid state, respectively.

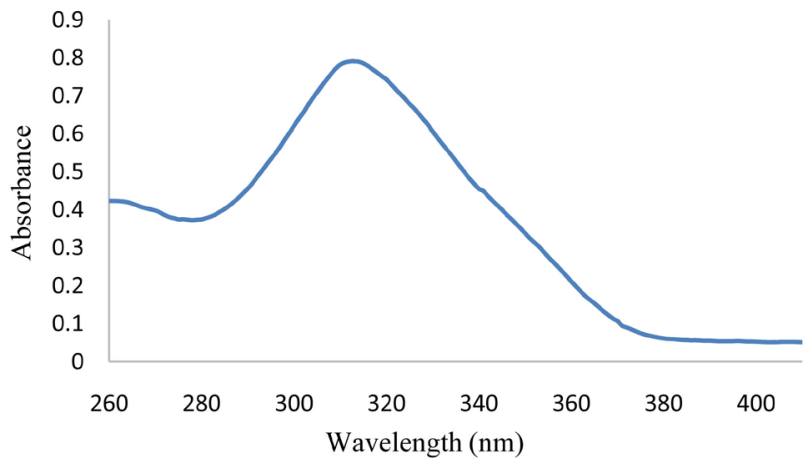

Figure 7. UV-Vis spectra of complex $3 \mathrm{~d}$.

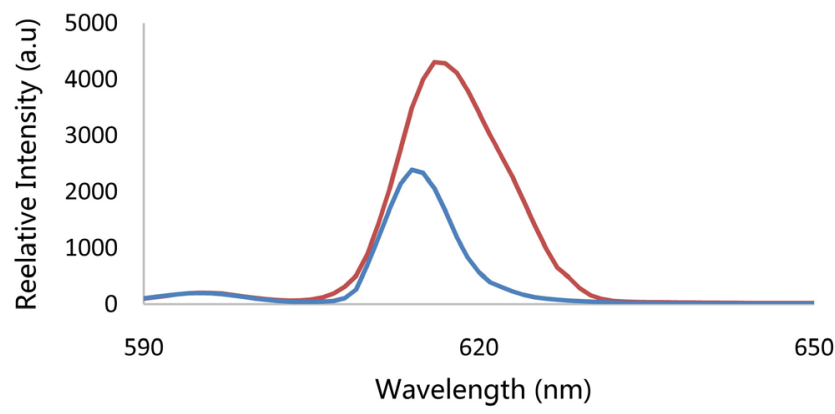

Figure 8. Emission spectra of complex $3 \mathrm{~d}$. Blue and red color represents, spectrum in solution and solid state, respectively. 

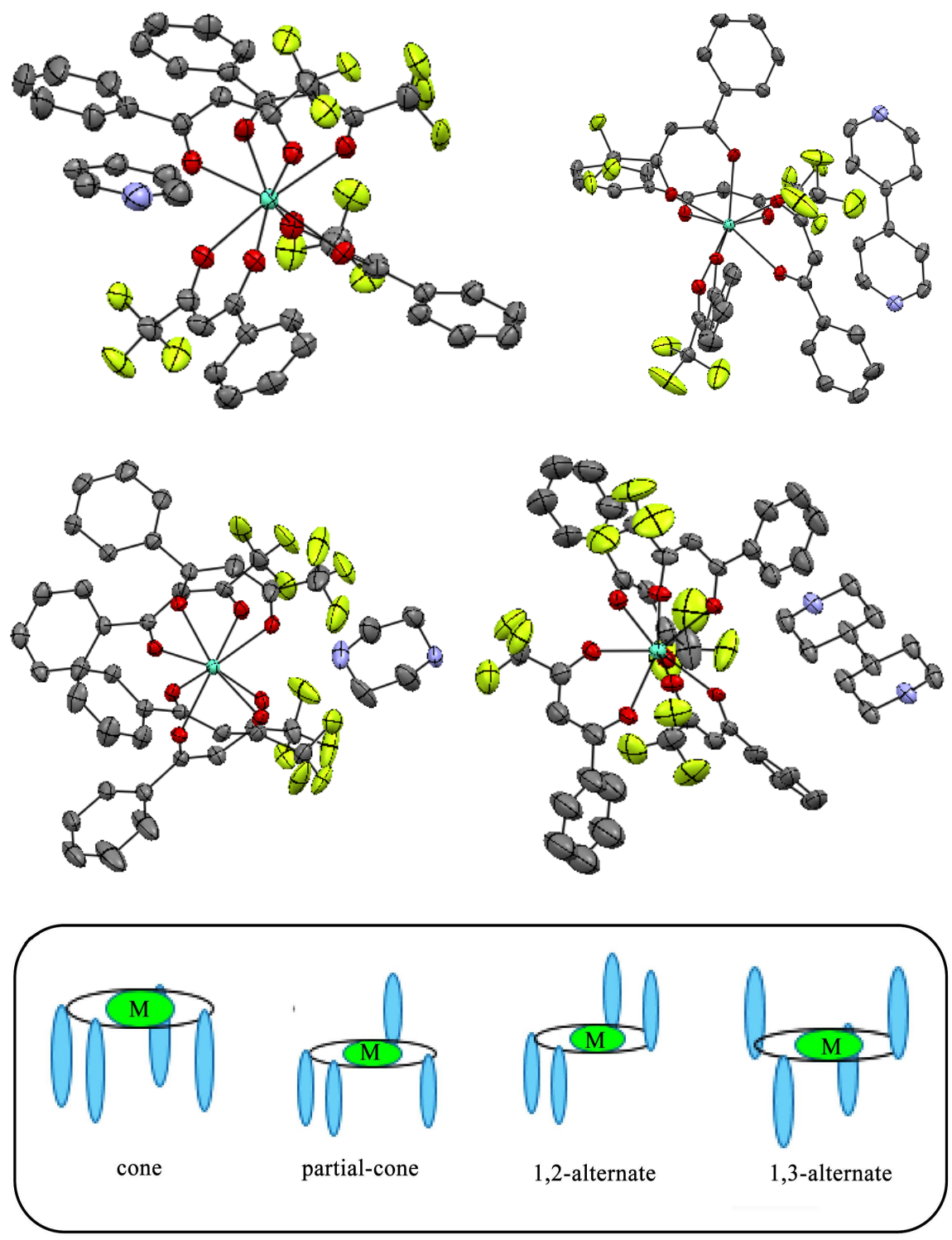

Figure 9. ORTEP view of the complexes $3 a, 3 b, 3 c$ and $3 d$. Ellipsoids are drawn at $50 \%$ probability level. Aqua blue, blue and red ellipsoids show Eu, N and $\mathrm{O}$ atom(s), respectively.

in unit cell with bipyridinium monocation. The complex $3 \mathrm{c}$ crystallized in monoclinic form with $C_{2 / C}$ space group and it has sixteen molecules in unit cell with piperazinium cation. The complex $\mathbf{3 d}$ also crystallized in monoclinic form with $P 2_{1} / n$ space group and it has two molecules in unit cell with bipiperidinium cation.

The europium (III) ions of four complexes are coordinated by a distorted octahedral arrangement of eight oxygen atoms from four chelating $\beta$-diketone ligands (Figure 10). The average Eu1-O bond lengths are moderately normal, and these values are $2.384 \AA$ for $3 a, 2.40 \AA$ for $3 b, 2.39 \AA$ for $3 c$ and $2.38 \AA$ for $3 d$, respectively (Tables 2-5). The bond distances and bond angles are in good agreement with those reported for other analogous $\mathrm{Eu}$ - $\beta$-diketone complexes [33]. 

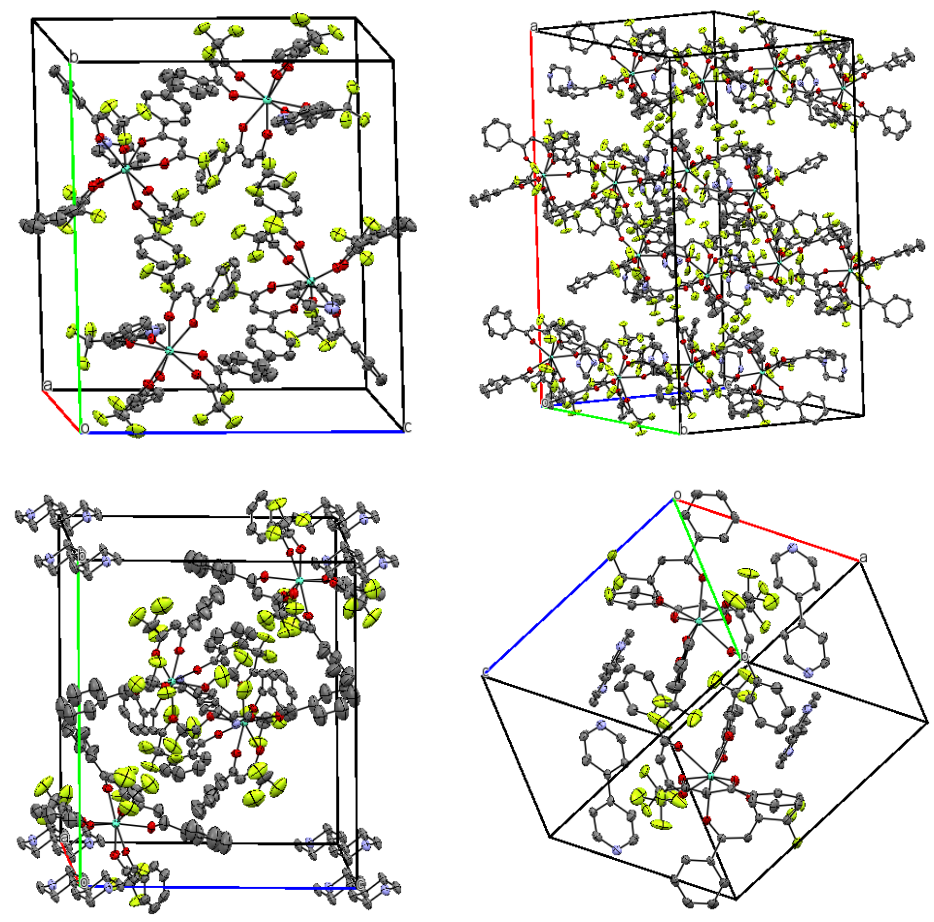

Figure 10. Crystal packing diagram of the complexes $3 \mathrm{a}, 3 \mathrm{~b}, 3 \mathrm{c}$ and $3 \mathrm{~d}$ respectively. Aqua blue, pale green, darkblue, red and green ellipsoids show $\mathrm{Eu}, \mathrm{F}, \mathrm{N}, \mathrm{O}$ and $\mathrm{Cl}$ atoms, respectively.

Table 2. Selected bond lengths $(\AA)$ and angles $\left({ }^{\circ}\right)$ for the complex 3 a.

\begin{tabular}{cccc}
\hline Eu1-O1 & $2.365(2)$ & Eu1-O2 & $2.390(2)$ \\
Eu1-O3 & $2.399(2)$ & Eu1-O4 & $2.370(2)$ \\
Eu1-O7 & $2.390(2)$ & Eu1-O8 & $2.394(4)$ \\
O1-Eu1-O2 & $91.6(7)$ & O3-Eu1-O4 & $81.92(6)$ \\
O7-Eu1-O8 & $149.53(7)$ & & \\
\hline
\end{tabular}

Table 3. Selected bond lengths $(\AA)$ and angles $\left({ }^{\circ}\right)$ for the complex $3 b$.

\begin{tabular}{cccc}
\hline Eu1-O1 & 2.392 & Eu1-O2 & 2.394 \\
Eu1-O3 & 2.408 & Eu1-O4 & 2.409 \\
O1-Eu1-O2 & 71.7 & O3-Eu1-O4 & 73.3 \\
O1-Eu1-O4 & 96.2 & O2-Eu1-O3 & 129 \\
\hline
\end{tabular}

Table 4. Selected bond lengths $(\AA)$ and angles $\left({ }^{\circ}\right)$ for the complex $3 c$.

\begin{tabular}{cccc}
\hline Eu1-O1 & $2.387(3)$ & Eu1-O2 & $2.412(2)$ \\
Eu1-O3 & $2.403(3)$ & Eu1-O4 & $2.370(3)$ \\
Eu1-O5 & $2.373(2)$ & Eu1-O6 & $2.354(3)$ \\
Eu1-O7 & $2.429(2)$ & O3-Eu1-O4 & $157.02(9)$ \\
O1-Eu1-O2 & $70.14(9)$ & O5-Eu1-O7 & $69.24(9)$ \\
O5-Eu1-O6 & $117.99(9)$ & & \\
\hline
\end{tabular}


Table 5. Selected bond lengths $(\AA)$ and angles $\left({ }^{\circ}\right)$ for the complex $3 \mathbf{d}$.

\begin{tabular}{cccc}
\hline Eu1-O1 & $2.375(7)$ & Eu1-O2 & $2.346(7)$ \\
Eu1-O3 & $2.401(6)$ & Eu1-O4 & $2.382(5)$ \\
Eu1-O5 & $2.424(7)$ & Eu1-O6 & $2.382(6)$ \\
Eu1-O7 & $2.377(6)$ & Eu1-O8 & $2.355(7)$ \\
O1-Eu1-O2 & $70.9(2)$ & O3-Eu1-O4 & $70.2(2)$ \\
O5-Eu1-O6 & $71.0(2)$ & O7-Eu1-O8 & $72.5(2)$ \\
\hline
\end{tabular}

\section{Conclusion}

In conclusion, four new europium complexes have been synthesized and characterized. Further, molecular structures and photoelectronic properties of four europium complexes were determined. All four complexes exhibited strong emission between $590-640 \mathrm{~nm}$, which could find prominent applications in light emitting devices. The absorbance and emission of the four complexes are quite the same. The fluorescence properties of all four crystals were very strong in solid state and very weak in solution state. These strong emissions were attributed to the ${ }^{5} \mathrm{D}_{0} \rightarrow{ }^{7} \mathrm{~F}_{0-4}$ transition of Europium (III) ions under UV excitation. To further improve the scope of applications of these complexes, introduction of electron withdrawing groups such as $-\mathrm{CN}$, $-\mathrm{F}$ on phenyl rings of fluorinated $\beta$-diketone ligand may improve the photoluminescence intensity and emission life time.

\section{Acknowledgements}

We are grateful to the Center for Instrumental Analysis, Kyushu Institute of Technology (KITCIA) for negative FAB-mass, and X-ray analysis.

\section{Conflicts of Interest}

The authors declare no conflicts of interest regarding the publication of this paper.

\section{References}

[1] Armelao, L., Quici, S., Barigelletti, F., Accorsi, G., Bottaro, G., Cavazzini, M. and Tondello, E. (2010) Design of Luminescent Lanthanide Complexes: From Molecules to Highly Efficient Photo-Emitting Materials. Coordination Chemistry Reviews, 254, 487-505. https://doi.org/10.1016/j.ccr.2009.07.025

[2] Hasegawa, Y., Kitagawa, Y. and Nakanishi, T. (2018) Effective Photosensitized Electrosensitized, and Mechanosensitized Luminescence of Lanthanide Complexes. NPG Asia Materials, 10, 52-70. https://www.nature.com/articles/s41427-018-0012-y https://doi.org/10.1038/s41427-018-0012-y

[3] Hasegawa, Y. and Kitagawa, Y. (2019) Thermo-Sensitive Luminescence of Lanthanide Complexes, Clusters, Coordination Polymers and Metal-Organic Frameworks with Organic Photosensitizers. Journal of Materials Chemistry C, 7, 7494-7511.

[4] Simon, A.C. and Harrowfield, J. (2012) Lanthanides: Biological Activity and Medi- 
cal Applications. In: Scott, R.A., Ed., Encyclopedia of Inorganic and Bioinorganic Chemistry, John Wiley \& Sons, Ltd., Hoboken. https://doi.org/10.1002/9781119951438.eibc2091

[5] Ruijie, D.T., John, T. and Harry, B.G. (2016) Lanthanides: Applications in Cancer Diagnosis and Therapy. Journal of Medicinal Chemistry, 59, 6012-6024. https://doi.org/10.1021/acs.jmedchem.5b01975

[6] Hiroshi, T. and Satoshi, S. (2002) Lanthanide Complexes in Molecular Recognition and Chirality Sensing of Biological Substrates. Chemical Reviews, 102, 2389-2404. https://doi.org/10.1021/cr010450p

[7] Pietraszkiewicz, O., Mal, S., Pietraszkiewicz, M., Maciejczyk, M., Czerski, I., Borowiak, T., Dutkiewicz, G., Drobchak, O., Penninck, L., Beeckman, J. and Neyts, K. (2012) Highly Photoluminescent Eu(III) Complexes of the New 1-Triphenylen-2yl-3-Trifluoroacetylacetone. Journal of Photochemistry and Photobiology A: Chemistry, 250, 85-91. https://doi.org/10.1016/j.jphotochem.2012.10.003

[8] Anderson, I.S.S., Nathalia, B.D.L., Alfredo, M.S. and Simone, M.C.G. (2017) Europium Complexes: Luminescence Boost by a Single Efficient Antenna Ligand. ACS Omega, 2, 6786-6794. https://doi.org/10.1021/acsomega.7b00647

[9] Zheng, X., Wang, M. and Li, Q. (2018) Synthesis and Luminescent Properties of Europium Complexes Covalently Bonded to Hybrid Materials Based on MCM-41 and Poly(Ionic Liquids). Materials, 11, 677. https://doi.org/10.3390/ma11050677

[10] De Sá, G.F., Malta, O.L., De Mello Donegá, C., Simas, A.M., Longo, R.L., Santa-Cruz, P.A. and Da Silva, E.F. (2000) Spectroscopic Properties and Design of Highly Luminescent Lanthanide Coordination Complexes. Coordination Chemistry Reviews, 196, 165-195. https://doi.org/10.1016/S0010-8545(99)00054-5

[11] Zhang, Y., Shi, H., Ke, Y. and Cao, Y. (2007) Synthesis and Characterization of Highly Fluorescent Europium Functionalized $\beta$-Diketonate Complexes. Journal of Luminescence, 124, 51-57. https://doi.org/10.1016/j.jlumin.2006.01.361

[12] Azab, H.A., Khairy, G.M. and Kamel, R.M. (2015) Time-Resolved Fluorescence Sensing of Pesticides Chlorpyrifos, Crotoxyphos and Endosulfan by the Luminescent Eu(III)-8-allyl-3-Carboxycoumarin Probe. Spectrochimica Acta Part A: Molecular and Biomolecular Spectroscopy, 148, 114-124. https://doi.org/10.1016/j.saa.2015.03.098

[13] Kaczmarek, A.M., Liu, Y.-Y., Wang, C., Laforce, B., Vincze, L., Van Der Voort, P., Van Hecke, K. and Van Deun, R. (2017) Grafting of a Eu ${ }^{3+}$-tfac Complex on to a $\mathrm{Tb}^{3+}$-Metal Organic Framework for Use as a Ratiometric Thermometer. Dalton Transactions, 46, 12717-12723. https://doi.org/10.1039/C7DT02042B

[14] Gaspar, R.D.L., Fortes, P.R., Mazali, I.O., Sigoli, F.A. and Raimundo Jr, I.M. (2018) Optical Temperature Sensors Based On Europium (III) Beta-Diketonate Complexes Chemically Bonded to Functionalized Polydimethylsiloxane. ChemistrySelect, 3, 10491-10501. https://doi.org/10.1002/slct.201801373

[15] Li, X., Gu, J., Zhou, Z., Ma, L., Tang, Y., Gao, J. and Wang, Q. (2019) New Lanthanide Ternary Complex System in Electrospun Nanofibers: Assembly, Physico-Chemical property and Sensor Application. Chemical Engineering Journal, 358, 67-73. https://doi.org/10.1016/j.cej.2018.10.003

[16] Lu, G., Kong, X., Wang, C., Zhao, L., Qi, D., Jiang, Y., Zhao, S., Chen, Y. and Jiang, J. (2019) Optimizing the Gas Sensing Properties of Sandwich-Type Phthalocyaninato Europium Complex through Extending the Conjugated Framework. Dyes and Pigments, 161, 240-246. https://doi.org/10.1016/j.dyepig.2018.09.062

[17] Liu, X., Guo, L., Song, B., Tang, Z. and Yuan, J. (2017) Development of a Novel Eu- 
ropium Complex-Based Luminescent Probe for Time-Gated Luminescence Imaging of Hypochlorous Acid in Living Samples. Methods and Applications in Fluorescence, 5, Article ID: 014009. https://doi.org/10.1088/2050-6120/aa61af

[18] Wu, H. and Tong, C. (2018) A Specific Turn-On Fluorescent Sensing for Ultrasensitive and Selective Detection of Phosphate in Environmental Samples Based on Antenna Effect-Improved FRET by Surfactant. ACS Sensors, 3, 1539-1545. https://doi.org/10.1021/acssensors.8b00343

[19] Ma, H., Wang, X., Song, B., Wang, L., Tang, Z., Luo, T. and Yuan, J. (2018) Extending the Excitation Wavelength from UV to Visible Light for a Europium Complex-Based Mitochondria Targetable Luminescent Probe for Singlet Oxygen. Dalton Transactions, 47, 12852-12857. https://doi.org/10.1039/C8DT02829J

[20] Fuchi, Y., Fukuda, T. and Sasaki, S. (2018) Luminescent Europium Sensors for Specific Detection of 8-oxo-dGTP by Time-Gated Fluorescence. Bioorganic \& Medicinal Chemistry, 26, 3254-3260. https://doi.org/10.1016/j.bmc.2018.04.052

[21] Kharcheva, A.V., Kapitonova, M.A., Farat, O.K., Borisova, N.E. and Patsaeva, S.V. (2019) The Interaction of the Europium Complex with Human Serum Albumin. International Symposium on Optics and Biophotonics VI: Saratov Fall Meeting 2018, Saratov, 24-29 September 2018, 11065P.

https://doi.org/10.1117/12.2523257

[22] Manju, B., Satish, K., Taxak, V.B., Priti, B. and Khatkar, S.P. (2015) Synthesis, Photoluminescent Features and Intramolecular Energy Transfer Mechanism of Europium (III) Complexes with Fluorinate b-Diketone Ligand and Auxiliary ligands. Journal of Fluorine Chemistry, 178, 6-13. https://doi.org/10.1016/j.jfluchem.2015.06.011

[23] Khalil, G.E., Lau, K., Phelan, G.D., Carlson, B. and Gouterman, M. (2004) Europium Beta-Diketonate Temperature Sensors: Effects of Ligands, Matrix, and Concentration. Review of Scientific Instruments, 75, 192. https://doi.org/10.1063/1.1632997

[24] Wang, D., Liu, H., Fan, L., Yin, G., Hu, Y. and Zheng, J. (2015) Synthesis and Photoluminescent Behavior of $\mathrm{Eu}(\mathrm{III})$ Complexes with 4,4,4-Trifluoro-1-(6-methoxynaphthalen-2-yl)-butane-1,3-dione. Synthetic Metals, 209, 267-272. https://doi.org/10.1016/j.synthmet.2015.08.002

[25] Martins, J.P., Martín-Ramos, P., Coya, C., Silva, M.R., Eusebio, M.E.S., deAndrés, A., Álvarez, A.D. and Martín-Gil, J. (2015) Highly Luminescent Pure-Red-Emitting Fluorinated $\beta$-Diketonate Europium(III) Complex for Full Solution-Processed OLEDs. Journal of Luminescence, 159, 17-25. https://doi.org/10.1016/j.jlumin.2014.10.020

[26] Iwanaga, H. (2019) A CF3-Substituted Diphosphine Dioxide Ligand That Enhances Both Photoluminescence Intensity and Solubility of Eu(III) Complexes. Journal of Alloys and Compounds, 790, 296-304. https://doi.org/10.1016/j.jallcom.2019.03.085

[27] Moriguchi, T., Hirosaki, S., Venkataprasad, J., Tsuge, A. and Yoza, K. (2017) The Syntheses, Crystal Structure and Luminescence Properties of Cone-Like Octadentate Europium (III) Complexes with Four Short Alkoxy Substituents. Crystals, 7, 85-93. https://doi.org/10.3390/cryst7030085

[28] Moriguchi, T., Kitou, N., Yakeya, D., Tsuge, A., Yoza, K. and Venkataprasad, J. (2017) Syntheses, Crystal Structure and Photoluminescence Properties of Piperidinium Tetrakis (1,3-Diphenyl-1,3-Propanedionato) Europate(III) Complex and Its Two Different Crystals. Crystal Structure Theory and Applications, 6, 57-66. http://www.scirp.org/journal/csta 
https://doi.org/10.4236/csta.2017.64005

[29] Bruker AXS (2009) APEX2 Version 2009.9. Bruker AXS Inc., Tokyo.

[30] Bruker AXS (2009) SAINT Version 7.68A. Bruker AXS Inc., Tokyo.

[31] Sheldrick, G.M.A. (2008) A Short History of SHELX. Acta Crystallographica Section $A, 64,112-122$. https://doi.org/10.1107/S0108767307043930

[32] Melby, L.R., Rose, N.J., Abramson, E. and Caris, J.C. (1964) Synthesis and Fluorescence of Some Trivalent Lanthanide Complexes. Journal of the American Chemical Society, 86, 5117-5125. https://doi.org/10.1021/ja01077a015

[33] Zhang, L., Li, B., Zhang, L., Chen, P. and Liu, S. (2009) Synthesis, Characterization, and Luminescent Properties of Europium Complexes with Fluorine Functionalized Phenanthroline. Journal of the Electrochemical Society, 156, H202-H207. https://doi.org/10.1149/1.3060228 